\title{
Ga-68: A Versatile PET Imaging Radionuclide
}

\section{Jaya Shukla, BR Mittal}

\begin{abstract}
Gallium-68, a positron emitter, is a vailable via ${ }^{68} \mathrm{Ge} /{ }^{68} \mathrm{G}$ a generators. The simple chemistry and easy availability has increased its application from the clinical diagnosis to personalized therapy and has lot more potential in future.
\end{abstract}

Keywords: ${ }^{68} \mathrm{Ge} /{ }^{68} \mathrm{G}$ a generator, Cyclotron, Bifunctional chelators, Nanoparticles.

How to cite this article: Shukla J , Mittal BR. Ga-68: A Versatile PET Imaging Radionuclide. J Postgrad Med Edu Res 2013;47(1):74-76.

\section{Source of support $\mathrm{Nil}$}

Conflict of interest: None declared

\section{INTRODUCTION}

The availability of ${ }^{68} \mathrm{G}$ a as a positron emission tomography (PET) radionuclide for imaging dates back to early $60^{\prime} \mathrm{s}$ at a time when neither PET nor fluorine-18 (F-18) was established. With the emergence of cyclotron and automated chemistry modules, F-18 radiopharmaceuticals established their empire in nuclear medicine. The resurgence of ${ }^{68} \mathrm{Ge} /$ ${ }^{68} \mathrm{G}$ a generator was due to the consistent efforts by radiochemists from Czechoslovakia and Russia in 20th century. ${ }^{1,2}$ The modern ${ }^{68} \mathrm{Ge} /{ }^{68} \mathrm{G}$ a generators have proved to be a milestone for noninvasive state-of-art PET/CT imaging. After that there was no looking back for $\mathrm{Ga}-68$ imaging.

The advantages of ${ }^{68} \mathrm{G}$ a over other PET-based radionuclides are its availability from an in-house generator independent of an onsite cyclotron. The half-life of $\mathrm{Ga}-68$ is 68 minutes. Eighty-nine percent of $\mathrm{Ga}-68$ decays by emitting positron of $1.92 \mathrm{M} \mathrm{eV}$ and the rest $11 \%$ by electron capture. The parent ${ }^{68} \mathrm{Ge}$ is produced in accelerator by $(p, 2 n)$ reaction on $\mathrm{Ga}_{2} \mathrm{O}_{3}$ target. ${ }^{68} \mathrm{G}$ e decays with a halflife of 270.8 days by electron capture which enable long shelf life to generator ( $>6$ months) and reduces the unitdose cost. Due to short half life, Ga- 68 can be eluted 2 to 3 times a day (after 3-5 hours) as per the requirement/patients number.

\section{${ }^{68} \mathrm{Ge} /{ }^{68} \mathrm{Ga}$ GENERATOR SYSTEM}

In ${ }^{68} \mathrm{Ge} /{ }^{68} \mathrm{G}$ a generator system, ${ }^{68} \mathrm{Ge}$ is strongly adsorbed on different solid supports such as, metal oxides $\left(\mathrm{Al}_{2} \mathrm{O}_{3}\right.$, $\mathrm{TiO}_{2}$ or $\mathrm{SnO}_{2}$ ), organic (pyrogallol-formaldehyde resins) and inorganic supports (silica based). ${ }^{3-6}$ The Ga-68 from currently available ${ }^{68} \mathrm{G} \mathrm{e} /{ }^{68} \mathrm{G}$ a generators is eluted with dilute hydrochloric acid as a cationic ${ }^{68} \mathrm{Ga}^{3+}$. Initially the long processing was required to remove metallic impurities of solid support and Ge-68 breakthrough from $\mathrm{Ga}$-68 elute. With the development of nonmetallic silica-based column, the processing step for the el ution of $\mathrm{G}$ a-68 was eliminated. Silica has high binding affinity for $G e$ which reduces the Ge-68 breakthrough to negligible level.

\section{APPLICATION OF ${ }^{68} \mathrm{Ga}^{3+}$}

Gallium acts as an iron analog and binds to transferrin and lactoferrin. The complex diffuses through loose endothelial junctions of capillaries at the sites of inflammation and enters the extracellular fluid. Leukocytes also migrate to sites of inflammation, degranulate and release large quantities of lactoferrin. $\mathrm{Ga}$ attaches to siderophores of bacteria and therefore can be used in leukopenic patients with bacterial infection and also in detecting sterile abscesses that provoke a leukocyte response. ${ }^{7}$ In earlier times, Ga-67 citrate was very popular for infection imaging by exploiting above properties of $\mathrm{Ga} .{ }^{8}$ D ue to low energy, long imaging time (half life: 78 hours) and poor image quality, the impact of Ga-67 imaging faded away. The resurgence of $\mathrm{Ga}-68$, a PET radionuclide has revived the importance of ${ }^{68} \mathrm{G}$ a as natural invivo infection/inflammation imaging agent, ${ }^{9,10} \mathrm{~N}$ ow, the infection imaging is done using ${ }^{68} \mathrm{G}$ a-citrate and ${ }^{68} \mathrm{GaCl}_{3}$.

\section{${ }^{68} \mathrm{Ga}^{3+}$ CHEMISTRY}

${ }^{68} \mathrm{G}$ a-complexes has simple aqueous coordinate chemistry based on $\mathrm{Me}(\mathrm{III}){ }^{11} \mathrm{Gallium}$, in aqueous solution, occurs solely in +3 oxidation state and is classified as a hard acid metal. Gallium can bond to highly ionic hard base ligand donors, such as carboxylic acids, amino nitrogens, hydroxamates, thiols and phenolates. The Ga chemistry is highly influenced by $\mathrm{pH}$ change. The optimum pH (3-5) is required for its aqueous chemistry. The $\mathrm{pH}$ below optimum inhibits the reaction and at $\mathrm{pH}$ above optimum range, i.e. $>5$, it tends to hydrolyze and leads to the precipitation as $\mathrm{Ga}(\mathrm{OH})_{3}$.

\section{Ga-68-LABELED MOLECULES}

Several suitable bifunctional chelators have been developed, and coupled with biomolecules for Ga-68 labeling. DOTA , NOGADA and NOTA are commonly used bifunctional chelators. M any peptides/biomolecules like receptor 
peptides and antibodies etc have now been successfully modified by these chelating agents without compromising their functional properties which further widened the role of Ga-68 PET/CT imaging. These peptides/biomolecules show very fast target localization and fast blood clearance thus, making the short half-life ideal for clinical studies. In the last decade ${ }^{68} \mathrm{Ga}$-DOTA-octreotides replaced ${ }^{99 \mathrm{~m}} \mathrm{Tc} /{ }^{111}$ In-DTPA-octroescan used for neuroendocrine tumor (NET) imaging. ${ }^{68} \mathrm{Ga-DOTA}$-octreotides proved to bea promising radiopharmaceutical for diagnosis, treatment planning, therapy response evaluation and disease recurrence of NET. ${ }^{12}$ Several peptides like somatostatin for imaging NET, integrin peptide for imaging neoangiogenesis, etc. are now available as cold kits.

Ga-68 labeling has also been explored with other peptide receptors, like cholecystokinin/gastrin and GLP-1 analogs for NETs, bombesin and neuropeptide-Y analogs for prostate or breast cancers. ${ }^{13-15} \mathrm{~A} \mathrm{rg}$-G ly-A sp (RGD) a cyclic tripeptide is used to image neoangiogenic/angiogenic vessels and mediated cell adhesion molecule by targeting overexpressed $\alpha_{v} \beta_{3}$ integrin. Inflammatory bowel disease, inflamed synovial tissue of rheumatoid arthritis and inflammatory atherosclerotic plaques can al so be visualized by ${ }^{68} \mathrm{Ga}-\mathrm{RGD}$ peptide. ${ }^{16} \mathrm{~V}$ ascular adhesion protein-I (VAP 1) is an inflammation inducible endothelial cell molecule. It also contributes to extravasation cascade and controls trafficking of leukocyte at the site of inflammation. VAP-1 is expressed on the endothelial surface of intestinal blood vessels in inflammatory diseases, in skin inflammation (psoriasis), synovial blood vessels of inflamed joints (rheumatic arthritis) and cardiovascular diseases. H owever, VAP-1 is absent from the endothelial surface of normal tissues. Ga-68-labeled peptide against VAP-1 have been used for in vivo imaging of VA P-1 knockout. ${ }^{17}$

\section{FUTURE}

In the modern era of 'personalized medicine', Ga-68 has a promising role. The targets can be defined with the help of diagnostic Ga-68 PET/CT using appropriate ligands (peptides/biomolecules) for detection of disease, pretherapeutic measurement of organ and tumor doses. The therapeutic analog of imaging radionuclide ( $\mathrm{Lu}-177 / \mathrm{Y}-90)$ can be selected for therapy using the same peptide. $\mathrm{N}$ anomedicine in future has a great potential for early detection, accurate diagnosis and personalized treatment of various diseases, particularly cancer. $\mathrm{N}$ anomedicine can offer unprecedented interactions with biomolecules, on the surface as well as inside the cells which may revolutionize disease diagnosis and treatment. Molecular imaging can measure the expression of molecular markers at different stages of diseases and provide relevant and reliable information in an intact system. The information may speed up the drug devel opment process and hel $p$ in individualized treatment monitoring and dose optimization. Ga-68 is an ideal radionuclide for labeling various nanoparticles like single-walled carbon nanotubes (SWNTs), quantum dots (QD), polymeric and metallic nanoparticles, etc. for evaluation of their biodistribution, pharmacokinetic properties and tumor targeting efficacy. ${ }^{18-20}$ The information may be utilized for early diagnosis, selecting better treatment options and predicting the disease prognosis.

With each passing day, the reign of Ga-68 in research and clinical application is increasingly being established. It has a lot in store for future. The easy availability and simple chemistry based on sophisticated chelating agents for $\mathrm{Ga}$ 68 will make it parallel to kit-based Tc-99m chemistry as predicted by Deutsch. ${ }^{21}$

\section{REFERENCES}

1. Kopecký P, M udrová B, Svoboda K. The study of conditions for the preparation and utilization of ${ }^{68} \mathrm{Ge}^{-68} \mathrm{G}$ a generator. Int J A ppl Radiat Isot 1973;24:73-80.

2. Schuhmacher J, Maier-B orst $\mathrm{W} .{ }^{68} \mathrm{Ge}-{ }^{68} \mathrm{Ga}$ generator for the production of ${ }^{68} \mathrm{Ga}$ in an ionic form. Int J Appl Radiat Isot 1974;25:263-68.

3. M irzadeh S, Lambrecht R. Radiochemistry of germanium. J Radioanal Nucl Chem 1996;202:7-102.

4. M eyer GJ, M aecke H, Schuhmacher J, K napp W H, H ofmann $\mathrm{M} .{ }^{68} \mathrm{G}$ a-labelled DOTA-derivatised peptide ligands. Eur J N ucl Med M ol Imag 2004;31:1097-104.

5. Velikyan I, B eyer GJ, L angstrom B. M icrowave-supported preparation of ${ }^{68} \mathrm{G}$ a bioconjugates with high specific radioactivity. Bioconjug Chem 2004;15:554-60.

6. Schuhmacher J, M aier-B orst W. A new ${ }^{68} \mathrm{Ge} /{ }^{68} \mathrm{G}$ a radioisotope generator system for production of ${ }^{68} \mathrm{Ga}$ in dilute $\mathrm{HCl}$. Int J A ppl Radiat Isot 1981;32:31-36.

7. El-M aghraby TA. Nuclear medicine methods for evaluation of skel etal infection among other diagnostic modalities. Q J N ucl Med M ol Imaging 2006;50:167-92.

8. Palestro CJ. The current role of gallium imaging in infection. Semin Nucl M ed 1994;24:128-41.

9. M äkinen TJ, Lankinen P, Pöyhönen $T$, Jalava J, A ro HT, Roivainen $\mathrm{A}$. Comparison of ${ }^{18} \mathrm{~F}-\mathrm{FDG}$ and ${ }^{68} \mathrm{Ga}$ PET imaging in the assessment of experimental osteomyelitis due to Staphylococcus aureus. Eur J Nucl Med Mol Imaging 2005;32:1259-68.

10. Silvola J, Laitinen I, Sipilä H, Laine VJO, Leppänen P, Y läHerttuala $S$, et al. U ptake of ${ }^{68}$ gallium in atherosclerotic plaques in LDLR/A poB 100/100 mice. EJNM M I Res 2011;1:14.

11. Green M A, W elch M J. Gallium radiopharmaceutical chemistry. Int J Rad Appl Instrum B 1989;16:435-48.

12. Naji M, AL-Nahhas $A \cdot{ }^{68} \mathrm{Ga}$-labelled peptides in the management of neuroectodermal tumours. Eur J Nucl M ed M ol Imaging 2012;39(Suppl 1):S61-67.

13. V on Guggen Berg E, Rangger C, Sosabowski J, Laverman P, Reubi JC, Virgolini IJ, et al. Preclinical evaluation of radiolabeled DOTA-derivatized cyclic minigastrin analogs for 
targeting cholecystokinin receptor expressing malignancies. M ol Imaging Biol 2012 J un;14(3):366-75.

14. Brom M, Oyen WJG, J oosten L, Gotthardt M, Boerman OC. Ga-labelled exendin-3, a new agent for the detection of insulinomas with PET. Eur J Nucl M ed Mol Imaging 2010; 37:1345-55.

15. Schuhmacher J, Zhang H, D oll J, M äcke HR, M atys R, H auser $H$, et al. GRP receptor-targeted PET of a rat pancreas carcinoma xenograft in nude mice with a 68Ga-labeled bombesin (6-14) analog. J N ucl M ed 2005;46:691-99.

16. Knetsch PA, Petrik $M$, Griessinger $C M$, Rangger $C, F$ ani $M$, Kesenheimer $C$, et al. [68Ga]N OD A GA -R GD for imaging $\alpha_{v} \beta_{3}$ integrin expression. Eur J Nucl Med Mol Imaging 2011;38: 1303-12.

17. A utio A, Ujula T, L uoto $P$, Salomäki S, J alkanen $S$, Roivainen A. PET imaging of inflammation and adenocarcinoma xenografts using vascular adhesion protein 1 targeting peptide (68)Ga-DOTA VA P-P1: Comparison with (18)F-FDG. Eur J Nucl M ed Mol Imag 2010;37:1918-25.

18. Liu Z, Cai W, He L, Nakayama N, Chen K, Sun X, et al. In vivo biodistribution and highly efficient tumor targeting of carbon nanotubes in mice. $\mathrm{N}$ at Nanotechnol 2007;2:47.
19. Cai W, Chen K, Li ZB, Gambhir SS, Chen X. Dual-function probe for PET and near-infrared fluorescence imaging of tumor vasculature. J N ucl M ed 2007;48:1862-70.

20. L ee HY, Li Z, Chen K, H su AR, Xu C, Xie J, et al. PET/MRI dual-modality tumor imaging using arginine-glycine-aspartic (RGD)-conjugated radiolabeled iron oxide nanoparticles. J Nucl M ed 2008;49:1371-79.

21. Deutsch E. Clinical PET: I ts time has come? J N ucl M ed 1993; 34:1132-33.

\section{ABOUT THE AUTHORS}

\section{Jaya Shukla (Corresponding Author)}

A ssistant Professor, D epartment of Nuclear M edicine, Postgraduate Institute of Medical Education and Research, Chandigarh, India e-mail: shuklajaya@gmail.com

\section{BR Mittal}

Professor and Head, Department of N uclear M edicine, Postgraduate Institute of M edical Education and Research, Chandigarh, India 